\title{
Arachidonoylcholine and Other Unsaturated Long-Chain Acylcholines Are Endogenous Modulators of the Acetylcholine Signaling System
}

\author{
Mikhail G. Akimov ${ }^{1, *,+}\left(\mathbb{D}\right.$, Denis S. Kudryavtsev ${ }^{1,+}\left(\mathbb{D}\right.$, Elena V. Kryukova ${ }^{1,+}$, \\ Elena V. Fomina-Ageeva ${ }^{1}$, Stanislav S. Zakharov ${ }^{1}$, Natalia M. Gretskaya ${ }^{1}$, Galina N. Zinchenko ${ }^{1}$, \\ Igor V. Serkov ${ }^{2}$, Galina F. Makhaeva ${ }^{2}$, Natalia P. Boltneva ${ }^{2}$, Nadezhda V. Kovaleva ${ }^{2}$, \\ Olga G. Serebryakova ${ }^{2}$, Sofya V. Lushchekina ${ }^{2,3}$, Victor A. Palikov ${ }^{1}$, Yulia Palikova ${ }^{1}$, \\ Igor A. Dyachenko $^{1} \mathbb{D}$, Igor E. Kasheverov ${ }^{1,4} \mathbb{D}$, Victor I. Tsetlin ${ }^{1}$ and Vladimir V. Bezuglov ${ }^{1}$ \\ 1 Department of molecular neuroimmune signaling, Shemyakin-Ovchinnikov Institute of Bioorganic \\ Chemistry, Russian Academy of Sciences, Moscow 117997, Russia; kudryavtsevden@gmail.com (D.S.K.); \\ evkr@mail.ru (E.V.K.); evfa57@gmail.com (E.V.F.-A.); xelor.craiz@gmail.com (S.S.Z.); \\ natalia.gretskaya@gmail.com (N.M.G.); zgn55@yandex.ru (G.N.Z.); vpalikov@bibch.ru (V.A.P.); \\ yuliyapalikova@bibch.ru (Y.P.); dyachenko@bibch.ru (I.A.D.); shak_ever@yahoo.com (I.E.K.); \\ victortsetlin3f@gmail.com (V.I.T.); vvbez2013@yandex.ru (V.V.B.) \\ 2 Department medicinal and biological chemistry, Institute of Physiologically Active Compounds, Russian \\ Academy of Sciences, Chernogolovka 142432, Moscow Region, Russia; serkoviv@mail.ru (I.V.S.); \\ galina.makhaeva@gmail.com (G.F.M.); boltneva@ipac.ac.ru (N.P.B.); kovalevanv@ipac.ac.ru (N.V.K.); \\ sog@ipac.ac.ru (O.G.S.); sofya.lushchekina@gmail.com (S.V.L.) \\ 3 Department of electrophysics of organic materials and nanostructures, Emanuel Institute of Biochemical \\ Physics, Russian Academy of Sciences, Moscow 119334, Russia \\ 4 Institute of Molecular Medicine, Sechenov First Moscow State Medical University, Moscow 119991, Russia \\ * Correspondence: akimovmike@gmail.com \\ + These authors contributed equally to this work.
}

Received: 7 January 2020; Accepted: 11 February 2020; Published: 12 February 2020

check for updates

\begin{abstract}
Cholines acylated with unsaturated fatty acids are a recently discovered family of endogenous lipids. However, the data on the biological activity of acylcholines remain very limited. We hypothesized that acylcholines containing residues of arachidonic (AA-CHOL), oleic (Ol-CHOL), linoleic (Ln-CHOL), and docosahexaenoic (DHA-CHOL) acids act as modulators of the acetylcholine signaling system. In the radioligand binding assay, acylcholines showed inhibition in the micromolar range of both $\alpha 7$ neuronal nAChR overexpressed in GH4C1 cells and muscle type $\mathrm{nAChR}$ from Torpedo californica, as well as Lymnaea stagnalis acetylcholine binding protein. Functional response was checked in two cell lines endogenously expressing $\alpha 7 \mathrm{nAChR}$. In SH-SY5Y cells, these compounds did not induce $\mathrm{Ca}^{2+}$ rise, but inhibited the acetylcholine-evoked $\mathrm{Ca}^{2+}$ rise with $\mathrm{IC}_{50} 9$ to $12 \mu \mathrm{M}$. In the A549 lung cancer cells, where $\alpha 7 \mathrm{nAChR}$ activation stimulates proliferation, Ol-CHOL, Ln-CHOL, and AA-CHOL dose-dependently decreased cell viability by up to $45 \%$. AA-CHOL inhibited human erythrocyte acetylcholinesterase (AChE) and horse serum butyrylcholinesterase (BChE) by a mixed type mechanism with $K_{i}=16.7 \pm 1.5 \mu \mathrm{M}$ and $\alpha K_{i}=51.4 \pm 4.1 \mu \mathrm{M}$ for AChE and $K_{i}=70.5 \pm 6.3 \mu \mathrm{M}$ and $\alpha K_{i}=214 \pm 17 \mu \mathrm{M}$ for $\mathrm{BChE}$, being a weak substrate of the last enzyme only, agrees with molecular docking results. Thus, long-chain unsaturated acylcholines could be viewed as endogenous modulators of the acetylcholine signaling system.
\end{abstract}

Keywords: nAChR; arachidonoylcholine; oleoylcholine; acylcholines; acetylcholinesterase 


\section{Introduction}

A system for the synthesis, reception, transport, and hydrolysis of acetylcholine (ACh) is present in most types of human cells [1]. In addition to the functions of a neurotransmitter, ACh regulates many processes, such as proliferation, differentiation, apoptosis, locomotor activity, angiogenesis, immune functions, secretion, organization of the cytoskeleton, and others [2]. Choline acetyltransferase, the key enzyme responsible for acetylcholine synthesis, is known to be unselective for the fatty acids that esterify choline. In rat brain, choline acetyltransferase exhibits the same affinity for butyryl-CoA and propionyl-CoA as for acetyl-CoA [3], leading to the production of propionylcholine and butyrylcholine in the presence of the respective precursor substances. Indeed, acetylcholine analogs with butyric, propionic, caproic, caprylic, and palmitic acids were identified in mammalian tissues [4-6]. As compared to $\mathrm{ACh}$, these compounds possessed weaker muscarinic-like activity and significantly stronger activity nicotinic-like activity [4] in physiological response tests.

Due to a low production rate and a lower affinity of these atypical esters for the ACh receptors, they are considered to be modulators of cholinergic signaling due to the desensitization of the receptors against the dominant signal molecule, acetylcholine [6].

Recently, novel ACh analogs with the chain length of 18 to 22 carbon atoms and various degree of unsaturation of fatty acid residue were discovered. Normal human plasma and urine contain choline derivatives with arachidonic, docosahexaenoic, oleic, linoleic, linolenic, and palmitic fatty acid residues [7]. More importantly, the increased content of long-chain unsaturated acylcholines was found in several diseases. Thus, oleic, linoleic, and arachidonic acid derivatives of choline were identified in the tissues of blood vessels obtained from the operations of patients suffering from cardiovascular diseases (abdominal aortic aneurysm, stenotic carotid plaques, femoral stenotic plaques, and intimal thickening) [8]. Arachidonoylcholine (AA-CHOL) was found in the profile of metabolites in atherosclerotic plaques and the adjacent intima of the arteries [9]. Acylcholines, especially the unsaturated ones, were increased in blood samples obtained from patients with a high risk of pulmonary embolism (PE) as compared with samples of patients with an intermediate risk of PE [10]. In addition, the increased level of eicosapentaenoylcholine correlated with the level of 25-hydroxy vitamin D in a study on osteoporosis control in Hong Kong [11].

The described data lead to a hypothesis that acetylcholine analogs with unsaturated long-chain fatty acid residue could play a significant role in disease formation. However, the data on the activity and targets for the long-chain unsaturated acylcholines are limited to a sea urchin Strongylocentrotus droebachiensis and S. purpuratus embryo development model. Unfertilized sea urchin eggs express ACh receptors resembling the neuronal nicotinic ACh receptors (nAChR) [12]. AA-CHOL and docosahexaenoylcholine (DHA-CHOL) dose-dependently induced the larva immobilization and cell lysis, and noncompetitive nicotinic cholinergic antagonist QX-222 quenched this effect [13]. Thus, AA-CHOL acted as a nAChR agonist or a cholinomimetic. However, the sea urchin ACh receptor-like protein is still poorly characterized, and therefore more data in mammalian models are required to understand the role of these compounds.

Considering the above facts, we hypothesized that fatty acid analogues of acetylcholine can function in the body as modulators of the acetylcholine system. To verify this assumption, we synthesized choline fatty acid esters with chain lengths C18, C20, and C22, namely oleic, linoleic, arachidonic, and docosahexaenoic acids. In this paper, we focused on the nicotinic acetylcholine system. We studied the ability of choline esters to interact with neuronal and muscle type acetylcholine receptors, determined the functionality of this interaction using cell cultures, checked the possible physiological effect of AA-CHOL in vivo, and also found out whether such acylcholines are substrates of acetylcholine hydrolysis enzymes and/or their inhibitors.

As the result, we show for the first time that arachidonoylcholine and its unsaturated fatty acid analogs with the chain length of 18 and 22 carbon atoms are inhibitors of the neuronal and muscle-type nicotinic receptors and modest inhibitors of the acetylcholinesterase (AChE, EC 3.1.1.7) and butyrylcholinesterase (BChE, EC 3.1.1.8), and thus could act as endogenous modulators of the acetylcholine signaling system. 


\section{Materials and Methods}

\subsection{Reagents}

L-Glutamine, fetal bovine serum, penicillin, streptomycin, amphotericin B, HEPES, Hanks' salts solution, trypsin, DMEM, (4,5-dimethylthiazol-2-yl)-2,5-diphenyltetrazolium bromide (MTT) were from PanEco, Moscow, Russia. HEPES, $\mathrm{KCl}, \mathrm{CaCl}_{2}, \mathrm{MgCl}_{2}$, DMSO, Triton X-100, D-glucose, non-essential amino acids, Hoechst 33258, human erythrocyte AChE, equine serum BChE, acetylthiocholine iodide, CHAPS, EDTA, dithiothreitol, PNU 120596, protease inhibitor cocktail, SCP0139, and 5,5'-dithio-bis-(2-nitrobenzoic acid) (DTNB) were from Sigma-Aldrich, St. Louis, MO USA. Arachidonic acid and Z-VAD-FMK were purchased from Cayman Europe, Hamburg, Germany. Ac-DEVD-AFC and Ac-LEHD-AFC were from Tocris Bioscience, Bristol, UK. Fluo-4AM and probenecid were from Thermo Fisher Scientific, Waltham, MA, USA.

\subsection{Animals}

Specific pathogen-free outbred ICR male mice (6 to 8 weeks old, weighing 29 to $33 \mathrm{~g}$ ) were obtained from the Animal Breeding Facility of the Branch of Shemyakin-Ovchinnikov Institute of Bioorganic Chemistry of the Russian Academy of Sciences (Pushchino). The animals had been acclimatized for 2 weeks before experimental procedures and were kept in two-corridor barrier rooms under a controlled environment: temperature 20 to $24{ }^{\circ} \mathrm{C}$, relative humidity $30 \%$ to $60 \%, 12 \mathrm{~h}$ light cycle. Animals were housed in standard polycarbonate cages Type $3\left(820 \mathrm{~cm}^{2}\right)$ on bedding (LIGNOCEL BK 8/15, JRS, Germany), with ad libitum access to feed (SSNIFF V1534-300, Spezialdiaeten, GmbH) and filtered tap water. Mouse cages were also supplied with material for environmental enrichment, Mouse House ${ }^{\mathrm{TM}}$ (Techniplast, Italy). The study was conducted in AAALAC (Association for Assessment and Accreditation of Laboratory Animal Care International) accredited facility in compliance with the standards of the Guide for Care and Use of Laboratory Animals (8th edition, Institute for Laboratory Animal Research). Animal treatment procedures were approved by the Institutional Animal Care and Use Committee (IACUC) of the Branch of the Shemyakin-Ovchinnikov Institute of Bioorganic Chemistry, Russian Academy of Sciences, the experimental protocol code is no. 700/19.

\subsection{Chemical Synthesis}

Dimethylaminoethanol esters of arachidonic (AA-DMAE), docosahexaenoic (DHA-DMAE), linoleic (Ln-DMAE), and oleic (Ol-DMAE) acids were obtained by the treatment of corresponding fatty acid chloride with $\beta-N, N$-dimethylaminoethanol as described in [13]. AA-CHOL, DHA-CHOL, Ol-CHOL, and Ln-CHOL were synthesized by treatment and AA-DMAE, DHA-DMAE, Ol-DMAE, and Ln-DMAE with methyl iodide as described in [13]. The compound purities were 95\% to $97 \%$.

\subsection{Cell Culture}

SH-SY5Y cells (ATCC CRL-2266) were maintained in the DMEM medium supplemented with 10\% of fetal bovine serum, $4 \mathrm{mM}$ of L-glutamine, and 1\% of non-essential amino acids. The A549 cells (ATCC CCL-185) were maintained in DMEM medium supplemented with $2 \mathrm{mM}$ of L-glutamine and $10 \%$ of fetal bovine serum. All cell medium contained $100 \mathrm{U} / \mathrm{mL}$ of penicillin, $100 \mu \mathrm{g} / \mathrm{mL}$ of streptomycin, and $2.5 \mu \mathrm{g} / \mathrm{mL}$ of amphotericin B. The cells were cultured in an atmosphere of $95 \%$ humidity and $5 \% \mathrm{CO}_{2}$ at $37^{\circ} \mathrm{C}$. Cells were passaged every 3 days and continuously grown for no more than 40 passages. Attached cells were detached with $0.25 \%$ trypsin in 0.53 mM EDTA in Hanks' salts. Cells were counted using a glass hemocytometer. The cells were routinely checked for mycoplasma contamination using Hoechst 33258 staining with microscopic detection. 


\subsection{Cytotoxicity Assay}

For the analysis of cell death induction, the cells were plated in 96-well plates at a density of $1.5 \times 10^{4}$ cells per well and grown overnight. The dilutions of test compounds prepared in DMSO and dissolved in the culture medium were added to the cells in triplicate for each concentration so that every well contained $100 \mu \mathrm{L}$ of conditioned medium and $100 \mu \mathrm{L}$ of fresh medium with the test substance and incubated for $18 \mathrm{~h}$. The incubation time was chosen based on the most pronounced differences between the compounds tested. The final DMSO concentration was $0.5 \%$. Negative (all cells alive) control cells were treated with $0.5 \%$ DMSO. Positive (all cells dead) control cells were treated with $3.6 \mu \mathrm{L}$ of $50 \%$ Triton $\mathrm{X}-100$ in ethanol per $200 \mu \mathrm{L}$ of cell culture medium. Separate controls were without DMSO (no difference with the control 0.5\% DMSO was found, data not shown). The effect of test substances on the cell viability was evaluated using the MTT test (based on the MTT dye reduction by mitochondria of living cells) [14].

\subsection{Caspase Activation Assay}

A549 cells were plated in 12-well plates at a density of $4 \times 10^{5}$ cells per well and grown overnight. The dilutions of test compounds prepared in DMSO and dissolved in the culture medium were added to the cells in triplicate for each concentration so that every well contained $400 \mu \mathrm{L}$ of conditioned medium and $400 \mu \mathrm{L}$ of fresh medium with the test substance and incubated for $5 \mathrm{~h}$. The final DMSO concentration was $0.5 \%$. After the incubation, the medium was collected and centrifuged for 5 min at 2000g; the pelleted dead cells and the remained attached cells were lysed with $200 \mu \mathrm{L}$ of the lysis buffer (250 mM HEPES, pH 7.4, 50 mM EDTA, 2.5\% CHAPS, 125 mM dithiothreitol, and protease inhibitor cocktail) per well for $10 \mathrm{~min}$ at $+4{ }^{\circ} \mathrm{C}$. The lysates were centrifuged for $15 \mathrm{~min}$ at $18,000 \mathrm{~g}$, at room temperature, and the pellets were discarded. Then, $50 \mu \mathrm{L}$ of each lysate was incubated with $50 \mu \mathrm{L}$ of the lysis buffer containing $50 \mu \mathrm{M}$ of the appropriate caspase fluorogenic substrate for $2 \mathrm{~h}$ at $37^{\circ} \mathrm{C}$ without stirring, after which the fluorescence was determined using the Hidex Sense Beta Plus microplate reader (Turku, Finland), $\lambda_{\mathrm{ex}} .=355 \mathrm{~nm}$ and $\lambda_{\mathrm{em}} \cdot=535 \mathrm{~nm}$.

\subsection{Apoptosis Assay}

A549 cells were plated in 48-well plates at a density of $1.5 \times 10^{4}$ cells per well and grown overnight. The dilutions of test compounds prepared in DMSO and dissolved in the culture medium were added to the cells in triplicate for each concentration so that every well contained $200 \mu \mathrm{L}$ of conditioned medium and $200 \mu \mathrm{L}$ of fresh medium with the test substance and incubated for $2 \mathrm{~h}$. The final DMSO concentration was $0.5 \%$. After the incubation, the cells were stained using a Apoptosis/Necrosis assay kit (Abcam, Cambridge, MA, USA) according to the manufacturer's protocol and imaged using a Nikon Ti-S fluorescent microscope.

\subsection{Calcium Mobilization Assay}

Cells were cultured for two days at $37^{\circ} \mathrm{C}$ on black 96 -well plates. Immediately before the experiments, cells were incubated with $2 \mathrm{mM}$ Fluo-4AM ester reagent and $1.25 \mathrm{mM}$ probenecid (organic anion transporter inhibitor) for $1 \mathrm{~h}$ at room temperature. After the incubation, the cells were washed out with the extracellular solution (140 mM NaCl, 2 mM CaCl $2,2.8 \mathrm{mM} \mathrm{KCl}, 4 \mathrm{mM} \mathrm{MgCl}$, 20 mM HEPES, 10 mM glucose; pH 7.4). The last washout was supplied with $10 \mathrm{uM} \alpha 7 \mathrm{nAChR}$ positive allosteric modulator PNU 120596 and tested compound. The excitation of Fluo-4 achieved at $485 \mathrm{~nm}$ and fluorescence registered at $535 \mathrm{~nm}$ using Hidex Sense Beta Plus (Turku, Finland) multi-well plate fluorimeter. The calcium rise amplitude was measured from the base level of each well.

\subsection{Radioligand Competition Assay of Acylcholines with Radioiodinated A-Bungarotoxin}

For radioligand competition assay, the targets were membrane-bound T. californica nAChR (kindly provided by Prof. F. Hucho, Institute for Chemistry and Biochemistry, Freie Universität Berlin, 
Germany), human $\alpha 7 \mathrm{nAChR}$ stably expressed in the rat pituitary tumor-derived cell line GH4C1 (received from Eli Lilly and Company, London, UK), and AChBP from L. stagnalis (kindly provided by Prof. S. Luo, Key Laboratory for Marine Drugs of Haikou, Hainan University, China).

We used suspensions of membranes from T. californica electric organ (1.25 $\mathrm{nM} \alpha$-bungarotoxin binding sites), $\alpha 7 \mathrm{nAChR}$-transfected GH4C1 cells $(0.4 \mathrm{nM})$, or the heterologously expressed L. stagnalis acetylcholine binding protein (AChBP) $(2.4 \mathrm{nM})$ in $50 \mu \mathrm{L}$ of binding buffer (Tris-HCl, $20 \mathrm{mM}$; BSA, $1 \mathrm{mg} / \mathrm{mL} ; \mathrm{pH} 8.0$ ). Ligands were added in various amounts and incubated with continuous shaking for $60 \mathrm{~min}$ at $20^{\circ} \mathrm{C}$. After that, ${ }^{125} \mathrm{I}-\alpha$-Bgt $(500 \mathrm{Ci} / \mathrm{mmol})$ was added at a final concentration of $0.1 \mathrm{nM}$, and samples were further incubated for $5 \mathrm{~min}$. The membranes or cell preparations were filtered through GF/C glass filters (Whatman, Maidstone, UK), washed, and bound radioactivity was measured using a Wallac 1470 Wizard Gamma Counter (PerkinElmer, Waltham, MA, USA). The AChBP samples were incubated with $10 \mu \mathrm{L}$ of $\mathrm{Ni}^{2+}$-NTA-agarose, and suspensions were filtered, washed, and bound radioactivity was measured as described above. The nonspecific ${ }^{125} \mathrm{I}-\alpha \mathrm{Bgt}$ binding was determined in the presence of a 200 -fold excess of $\alpha$-cobratoxin.

\subsection{Electrophysiology}

Oocytes were removed from mature Xenopus frogs treated with $2 \mathrm{mg} / \mathrm{mL}$ type "I" collagenase (Gibco, Life Technologies Corp., NY, USA) dissolved in a Ca ${ }^{2+}$-free ND96 buffer (5 mM HEPES, $2 \mathrm{mM}$ $\mathrm{MgCl}_{2}, 2 \mathrm{mM} \mathrm{KCl}$, and $96 \mathrm{mM} \mathrm{NaCl} ; \mathrm{pH} \mathrm{7.5).} \mathrm{After} 2$ to $4 \mathrm{~h}$ of collagenase treatment, oocytes were transferred to regular ND96 ( $5 \mathrm{mM}$ HEPES, $2 \mathrm{mM} \mathrm{MgCl}_{2}, 1.8 \mathrm{mM} \mathrm{CaCl}_{2}, 2 \mathrm{mM} \mathrm{KCl}$, and $96 \mathrm{mM} \mathrm{NaCl}$; $\mathrm{pH} 7.5$ ) and injected with 1 to $5 \mathrm{ng}$ of mouse muscle nAChR $\alpha 1, \beta 1, \delta$, and $\varepsilon$ subunit cDNA in pRBG4 vector; mouse $\alpha 1, \beta 3$, and $\gamma 2$ GABAAR subunits cDNA in PCI vector. Recordings were performed 24 to $72 \mathrm{~h}$ after injection. A Turbo TEC-03X amplifier (NPI electronic, Tamm, Germany) was used along with the WinWCP software.

\subsection{Assessment of the Cholinesterases Hydrolysis of AA-CHOL}

AChE and BChE hydrolysis of AA-CHOL was determined in $100 \mathrm{mM}$ phosphate buffer, $\mathrm{pH} 7.5$ at $25{ }^{\circ} \mathrm{C}$, the AA-CHOL concentration was $1 \mathrm{mM}$, the incubation time was $40 \mathrm{~min}$. The enzyme concentrations were $0.02 \mathrm{U} / \mathrm{mL}$ in the sample. The reverse phase HPLC method was used to estimate the hydrolysis of AA-CHOL. As a control, acetylthiocholine iodide (ATCh) hydrolysis was determined in the same conditions.

\subsection{Esterase Inhibition Assay}

$\mathrm{AChE}$ and BChE activities were determined by the colorimetric Ellman method ( $\lambda 412 \mathrm{~nm})$ [15], with some minor modifications as described in detail in [16], using ATCh $(1 \mathrm{mM})$ as substrate. The assay solution consisted of $0.1 \mathrm{M} \mathrm{K} / \mathrm{Na}$ phosphate buffer $\mathrm{pH} 7.5,25^{\circ} \mathrm{C}, 0.33 \mathrm{mM}$ DTNB, $0.02 \mathrm{unit} / \mathrm{mL}$ AChE or $\mathrm{BChE}$. Reagent blanks consisted of reaction mixtures without substrate. The measurements were carried out on a FLUOStar OPTIMA (BMG Labtech, Germany) microplate reader. The compounds were dissolved in DMSO, and the incubation mixture contained $2 \%$ of this solvent.

Preliminary evaluation of the inhibitory activity of the compounds was carried out by determining the degree of inhibition of enzymes at a compound concentration of $100 \mu \mathrm{M}$. For this, an enzyme sample was incubated with a test compound for $10 \mathrm{~min}$, then the residual enzyme activity was determined and compared with the enzyme activity without a tested compound. To determine the $\mathrm{IC}_{50}$, an enzyme sample was incubated with the test compound for $10 \mathrm{~min}$, then, the residual enzyme activity was determined. The concentration range of the test compound was $1 \times 10^{-8}$ to $1 \times 10^{-3} \mathrm{M}$. Origin 6.1 for Windows was used to determine $\mathrm{IC}_{50}$ values from plots of $\log$ (inhibitor concentration) vs. \% (residual activity). Results were expressed as mean $\pm \operatorname{SEM}(n=11$ experiments). 
2.13. Kinetic Analysis of AChE and BChE Inhibition by AA-CHOL: Determination of Steady-State Inhibition Constants

To elucidate the inhibition mechanisms for the active compound AA-CHOL, the AChE and BChE residual activities were determined in the presence of two increasing concentrations of AA-CHOL and six decreasing concentrations of the substrate. The test compound was preincubated with the enzymes at $25{ }^{\circ} \mathrm{C}$ for $10 \mathrm{~min}$, followed by the addition of ATCh. Parallel controls were made to find the rate of hydrolysis of the same concentrations of substrate in the solutions with no inhibitor. The kinetic parameters of substrate hydrolysis were determined. The measurements were carried out using a BioRad Benchmark Plus microplate spectrophotometer (France). Each experiment was performed in triplicate. The results were fitted into Lineweaver-Burk double-reciprocal kinetic plots of $1 / \mathrm{V}$ versus $1 /[\mathrm{S}]$ and the values of inhibition constants $K_{i}$ (competitive component) and $\alpha K_{i}$ (noncompetitive component) were calculated using Origin 6.1 software for Windows.

\subsection{In Vivo Myorelaxant Activity}

Tested AA-CHOL solution was injected into the triceps muscles of the mouse forelimbs at a volume of $0.5 \mathrm{~mL} / \mathrm{kg}$ per each limb or subcutaneously. For all animals, their forelimb grip strength was recorded before the substance administration with a 1027 grip strength meter (Columbus Instruments, Columbus, OH, USA). Their grip strength was measured 15, 30, 60,120, and 240 min after the AA-CHOL or saline administration.

\subsection{Molecular Docking}

Geometry of AA-CHOL was quantum-mechanically optimized with Gamess-US [17] software $\left(B 3 L Y P / 6-31 G^{*}\right)$. The optimized structure was used with partial atomic charges derived from QM results according to the Löwdin scheme. The most suitable for docking of bulky ligands [18] X-ray structure of human AChE, co-crystallized with donepezil PDB ID 4EY7 [19] and an optimized X-ray structure of human BChE (PDB ID 1P0I $[20,21]$ ) were used. Molecular docking was performed with AutoDock 4.2.6 software [22]. The grid box for docking included the entire active site gorge of AChE $(22.5 \AA \times 22.5 \times 22.5 \AA$. grid box dimensions $)$ and BChE $(15 \AA \times 20.25 \AA \times 18 \AA$ grid box dimensions $)$ with a grid spacing of $0.375 \AA$. The main Lamarckian genetic algorithm (LGA) [23] parameters were 256 runs, $25 \times 10^{6}$ evaluations, $27 \times 10^{4}$ generations, and a population size of 3000 .

Figures were prepared with PyMol (www.pymol.org).

\subsection{Statistical Procedures}

All experiments were conducted three times. GraphPad Prism 6.0 was used to plot the data and calculate $\mathrm{EC}_{50}$. The data were compared using ANOVA with the Holm-Sidak post-test; $p \leq 0.05$ was considered a statistically significant difference.

The radioligand assay results were analyzed with ORIGIN 8.0 (OriginLab Corporation, Northampton, MA, USA) fitting to a one-site dose-response curve by the equation: $\%$ response $=100 /\left\{1+\left(\left[\text { toxin] } / \mathrm{IC}_{50}\right)^{p}\right\}\right.$, where $\mathrm{IC}_{50}$ is the concentration at which $50 \%$ of the binding sites are inhibited, and $p$ is the Hill coefficient. Data in the radioligand assay are presented as mean with $95 \%$ confidence interval (CI).

\section{Results}

\subsection{Chemical Synthesis Of Acylcholines}

Choline esters of arachidonic (AA-CHOL), oleic (Ol-CHOL), linoleic (Ln-CHOL), and docosahexaenoic (DHA-CHOL) fatty acids (Figure 1) were synthesized via the dimethylaminoethanol ester intermediates according to the following scheme (Scheme 1), as was previously described [13]. The intermediate compounds were purified using low-pressure column silica chromatography, while target acylcholines were recovered after quaternization in a pure form by evaporation of reaction 
mixture. The structures were validated using ${ }^{1} \mathrm{H}-\mathrm{NMR}$. The reaction yields were about $50 \%$, and the obtained compound purities were $95 \%$ to $97 \%$ as was tested by reversed phase HPLC.

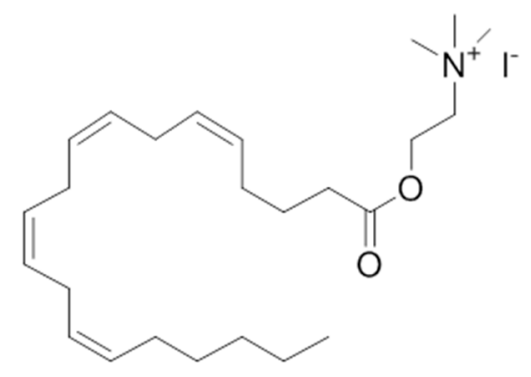

$\mathrm{AA}-\mathrm{CHOL}$

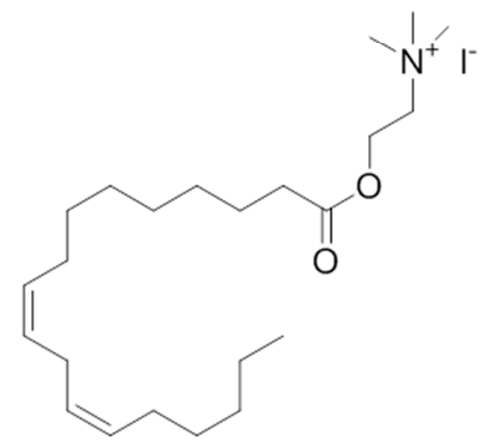

$\mathrm{Ln}-\mathrm{CHOL}$<smiles>CC/C=C\C/C=C\C/C=C\C/C=C\C/C=C\CCC(=O)OCC[N+](C)(C)C</smiles>

DHA-CHOL

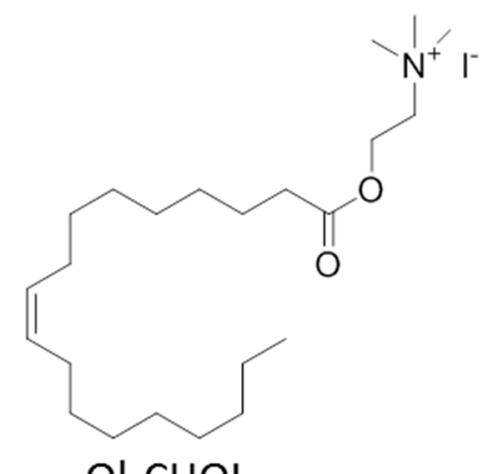

Figure 1. The structures of the synthesized acylcholines.

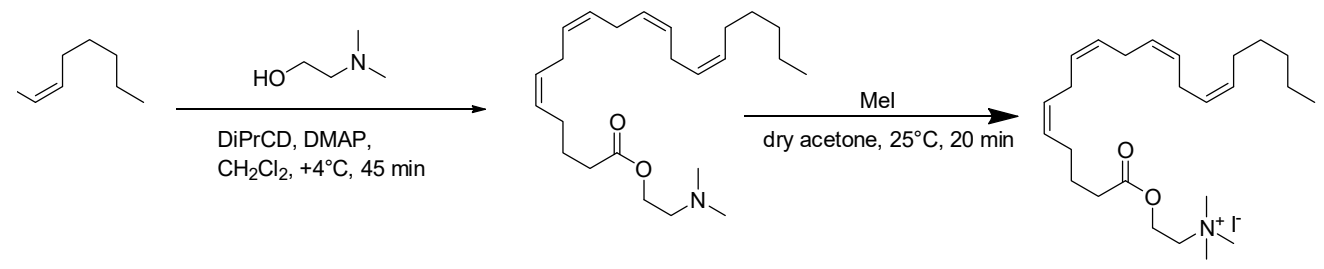

Scheme 1. Synthesis of aclylcholines on the example of AA-CHOL: DIPrCD, diisopropyl carbodiimide; DMAP, $N, N$,-dimethylaminopyridine [13].

\subsection{Acylcholines Interact with the A-Bungarotoxin Binding Site on $n A C h R$}

Using a radioligand assay, we studied acylcholines for their ability to compete with ${ }^{125} \mathrm{I}-\alpha \mathrm{Bgt}$ binding to the orthosteric sites of the nAChRs. At first, we tested the binding of acylcholines with the L. stagnalis AChBPs, which is the model for the ligand-binding domains of the whole family of Cys-loop receptors [24-26]. Ln-CHOL was the most active ( $\left.\mathrm{IC}_{50} 2.3 \mu \mathrm{M}\right)$ (Figure 2A, Table 1), whereas all three other compounds, as well as ACh, demonstrated activities only at five- to ten-fold higher concentrations ( $\mathrm{IC}_{50} \sim 13$ to $20 \mu \mathrm{M}$ ).

Since acylcholines could be expected to exhibit detergent properties to the nAChRs in the cell membranes, we tested the effect of the widely used detergent sodium dodecyl sulfate (SDS) on the ${ }^{125} \mathrm{I}-\alpha \mathrm{Bgt}$ binding. In the presence of $40 \mu \mathrm{M}$ SDS, the binding of ${ }^{125} \mathrm{I}-\alpha \mathrm{Bgt}$ to Torpedo membranes or GH4C1 cells did not differ from the control values (data not shown). After that, we studied the ability of acylcholines to compete with ${ }^{125} \mathrm{I}-\alpha \mathrm{Bgt}$ for binding to the full-size receptors, muscle-type nAChR from T. californica electric ray (Figure 2B) or human $\alpha 7 \mathrm{nAChR}$ (Figure 2C, Table 1). The Ln-CHOL, most efficient against the AChBP (having no membrane environment), was also most active against 
the Torpedo $\mathrm{nAChR}\left(\mathrm{IC}_{50} 18.7 \mu \mathrm{M}\right)$. At the same time, $\alpha 7 \mathrm{nAChR}$ was most efficiently inhibited by Ol-CHOL ( $\left.\mathrm{IC}_{50} 14.2 \mu \mathrm{M}\right)$.
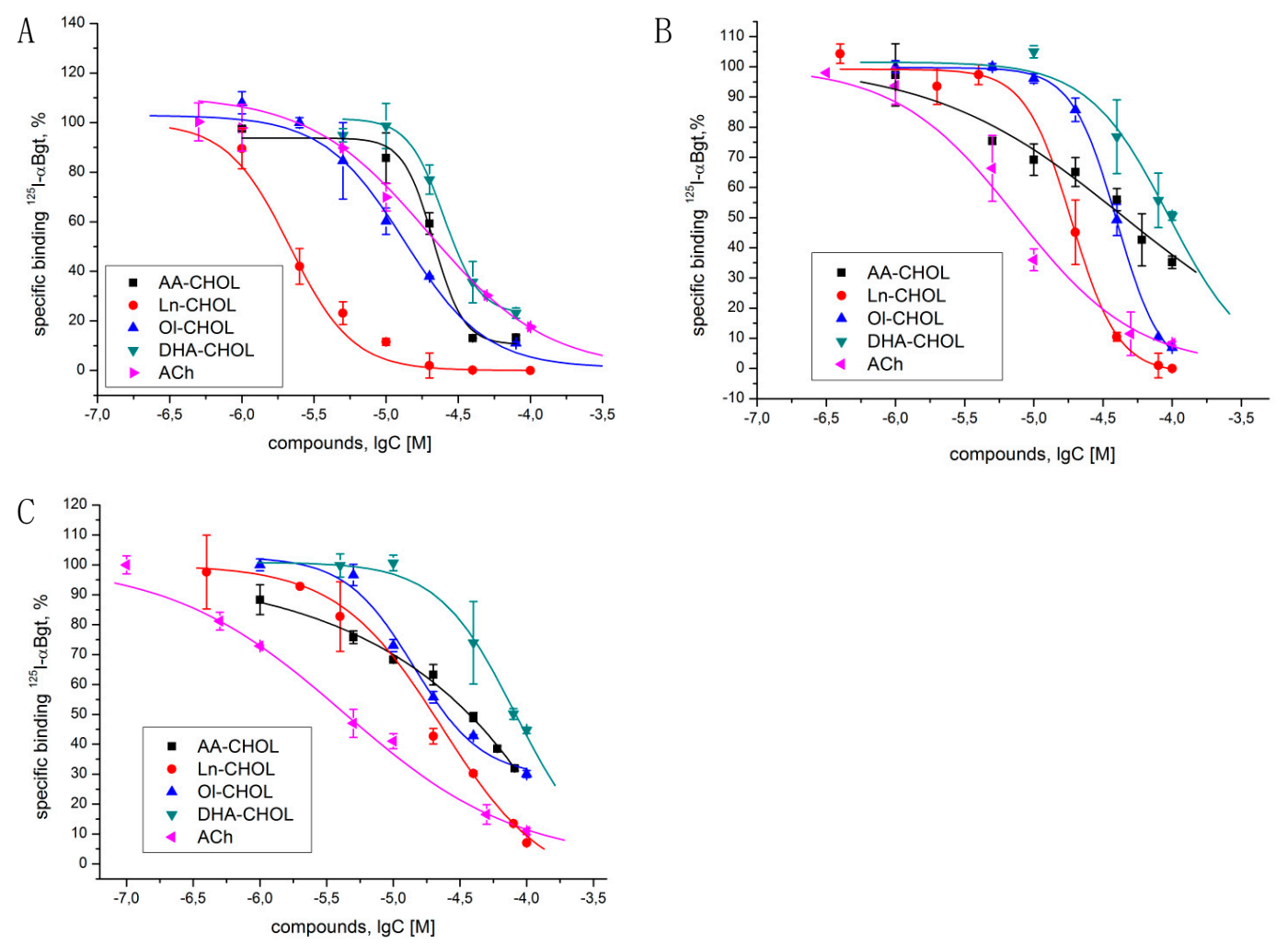

Figure 2. Competition of $\left[{ }^{125} \mathrm{I}\right]$-labeled $\alpha$ Bgt with acylcholines for binding to (A) L.stagnalis AChBP; (B) Torpedo californica nAChR; and (C) human $\alpha 7 \mathrm{nAChR}$ expressed in the GH4C1 cell line. $\mathrm{IC}_{50}$ values and $95 \%$ CIs are presented in Table 1 . Each point is the mean \pm SEM value of two measurements for each concentration in two (for DHA-CHOL with T. californica and $\alpha 7 \mathrm{nAChR}$ ) or three (all other cases) independent experiments.

Table 1. The results of ${ }^{125} \mathrm{I}-\alpha$ Bgt competition assay for acylcholines. The $\mathrm{IC}_{50}$ values presented (95\% CIs). In the ANOVA with Holm-Sidak post-test, the differences between all acylcholines on human a7 nAChR were significant with $p<0.05$ except for the pairs Ln-CHOL vs. Ol-CHOL and Ol-CHOL vs. ACh; on T. californica $\mathrm{nAChR}$, the differences between all acylcholines on human a7 $\mathrm{nAChR}$ were significant with $p<0.05$ except for the AA-CHOL and Ol-CHOL pair; on AChBP, only differences in pairs AA-CHOL vs. Ln-CHOL, Ln-CHOL vs. Ol-CHOL, Ln-CHOL vs. DHA-CHOL, Ln-CHOL vs. ACh, and Ol-CHOL vs. DHA-CHOL were significant with $p<0.05$.

\begin{tabular}{|c|c|c|c|}
\hline \multirow[t]{2}{*}{ Ligand } & \multicolumn{3}{|c|}{$\begin{array}{l}\mathrm{IC}_{50}, \mu \mathrm{M} \\
(95 \% \mathrm{CI})\end{array}$} \\
\hline & L. stagnalis AChBP & T. californica $\mathrm{nAChR}$ & human $\alpha 7$ nAChR \\
\hline AA-CHOL & $\begin{array}{c}21.3 \\
(17.1-26.5)\end{array}$ & $\begin{array}{c}47.6 \\
(34.9-58.1)\end{array}$ & $\begin{array}{c}35.9 \\
(31.3-41.2)\end{array}$ \\
\hline $\mathrm{Ln}-\mathrm{CHOL}$ & $\begin{array}{c}2.3 \\
(2.10-2.65)\end{array}$ & $\begin{array}{c}18.7 \\
(16.1-21.9)\end{array}$ & $\begin{array}{c}23.1 \\
(18.2-25.9)\end{array}$ \\
\hline Ol-CHOL & $\begin{array}{c}13.4 \\
(11.5-15.2)\end{array}$ & $\begin{array}{c}39.8 \\
(37.4-42.3)\end{array}$ & $\begin{array}{c}14.2 \\
(11.7-17.3)\end{array}$ \\
\hline DHA-CHOL & $\begin{array}{c}25.1 \\
(22.1-28.5)\end{array}$ & $\sim 93$ & $\sim 80$ \\
\hline $\mathrm{ACh}$ & $\begin{array}{c}20.1 \\
(15.8-25.5)\end{array}$ & $\begin{array}{c}7.6 \\
(5.97-9.33)\end{array}$ & $\begin{array}{c}4.29 \\
(2.77-6.67)\end{array}$ \\
\hline
\end{tabular}




\subsection{Acylcholines Inhibit nAChR Function}

The interaction of acylcholines with the nAChR's binding site for agonists and competitive antagonists shown by radioligand competition experiments could, in principle, induce receptor activation or, vice versa, inhibition of the activation due to competition with endogenous agonists acetylcholine and choline (in the case of $\alpha 7 \mathrm{nAChR}$ ). To find out whether the acylcholines act as agonists or antagonists, we performed fluorimetric measurements of cytoplasmic calcium evoked by activation of $n A C h R$. The ability of the compounds to induce calcium mobilization was studied in the SH-SY5Y cells endogenously expressing $\alpha 7 \mathrm{nAChR}$. Neither of the three tested compounds (AA-CHOL, Ln-CHOL, and DHA-CHOL) induced a rise in the intracellular $\mathrm{Ca}^{2+}$, and thus showed no agonistic properties towards this receptor. To test their antagonistic activity against $\alpha 7 \mathrm{nAChR}$, they were applied with ACh in the presence of PNU120596, a positive allosteric modulator of this homooligomeric $\mathrm{nAChR}$ subtype. All tested compounds at micromolar concentrations inhibited the acetylcholine-evoked $\mathrm{Ca}^{2+}$ rise in a concentration-dependent manner (Figure $3 \mathrm{~A}$ ). The $\mathrm{IC}_{50}$ values in this $\mathrm{Ca}^{2+}$ mobilization assay were in the range from 1 to $19 \mu \mathrm{M}$ for AA-CHOL, Ol-CHOL, Ln-CHOL, and DHA-CHOL (see Figure 3A). Thus, no significant influence of the fatty acid residue structure on the activity was found.

\section{$\mathbf{A}$}

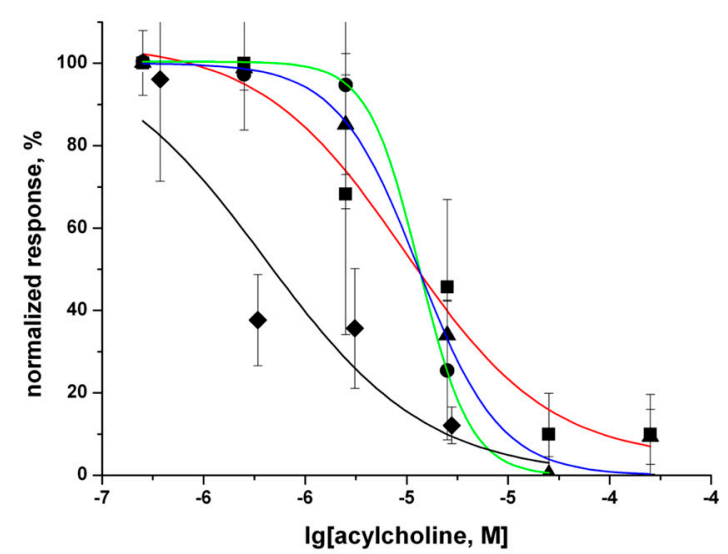

B

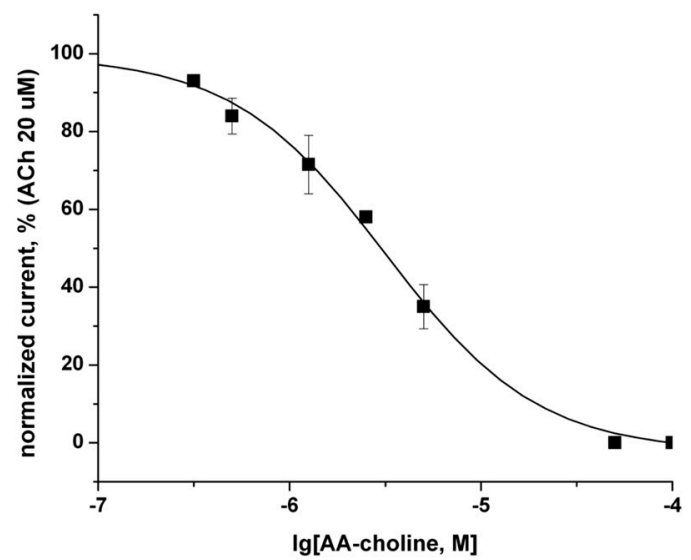

Figure 3. Inhibition of $\mathrm{nAChR}$ function by various acylcholines. (A) Inhibition curves for AA-CHOL (red line, squares), Ol-CHOL (blue line, triangles), Ln-CHOL (black line, diamonds), and DHA-CHOL (green line, circles) of $\mathrm{Ca}^{2+}$ influx evoked by acetylcholine in the presence of PNU 120596 on SH-SY5Y cell line. The $\mathrm{IC}_{50}$ values are listed in Table 2; (B) ACh evoked current in the mouse muscle nAChR expressed in Xenopus oocyte is inhibited by AA-CHOL at low micromolar concentrations $\left(\mathrm{IC}_{50} 3.16 \pm 0.26 \mu \mathrm{M}\right)$.

Table 2. Inhibition of acetylcholine-evoked $\mathrm{Ca}^{2+}$ mobilization in SH-SY5Y cells in the presence of PNU 120596, $\mathrm{IC}_{50}(\mu \mathrm{M})$. In the ANOVA with the Tukey post-hoc test, there were no statistically significant differences.

\begin{tabular}{ccc}
\hline Acylcholine & IC $_{\mathbf{5 0}}(\boldsymbol{\mu M})$ & $\mathbf{9 5 \%}$ Confidence Interval, $\boldsymbol{\mu M}$ \\
\hline AA-CHOL & 10 & $5-19$ \\
\hline Ol-CHOL & 12 & $9-14$ \\
\hline Ln-CHOL & 2 & $1-6$ \\
\hline DHA-CHOL & 11 & $10-14$ \\
\hline
\end{tabular}

AA-CHOL also inhibited mouse muscle nAChR expressed in Xenopus laevis oocytes (Figure 3B) with $\mathrm{IC}_{50}=3.16 \pm 0.26 \mu \mathrm{M}$. 
Previously, we have shown (including our paper [27]) that $\alpha$-bungarotoxin interacts with GABAAR in a way similar to its interaction with the acetylcholine-binding protein or the ligand-binding domain of nicotinic receptors. Therefore, we expected that AA-CHOL could have a similar activity. However, it showed no functional inhibition of $\alpha 1 \beta 3 \gamma 2$ GABAAR (Figure S5) up to a concentration of $10 \mu \mathrm{M}$. The higher concentrations of the substance in this experiment settings were considered to have only nonspecific effects, if any, and thus were not tested.

\subsection{In Vivo Muscle Relaxation Test}

The observation of muscle nAChR inhibition by AA-CHOL with micromolar affinity led us to the hypothesis that acylcholines acts as muscle relaxants at high doses. A possible muscle relaxant effect of the AA-CHOL was studied by measuring the mouse front legs strength at test points of $15 \mathrm{~min}, 30 \mathrm{~min}$, $1 \mathrm{~h}, 2 \mathrm{~h}$, and $4 \mathrm{~h}$, according to the protocol we previously used for azemiopsin, a peptide inhibitor of the muscle nAChR [28]. AA-CHOL was injected into the front paws in a volume of $20 \mu \mathrm{L}$ for each paw in doses of $0.5,1$, and $4 \mathrm{mg} / \mathrm{kg}$. The test group showed no differences from the control group (vehicle injection). We also tested AA-CHOL at higher doses using the subcutaneous injection of 10 and $30 \mathrm{mg} / \mathrm{kg}$. No differences with the respective controls (vehicle) were found (Figure 4).

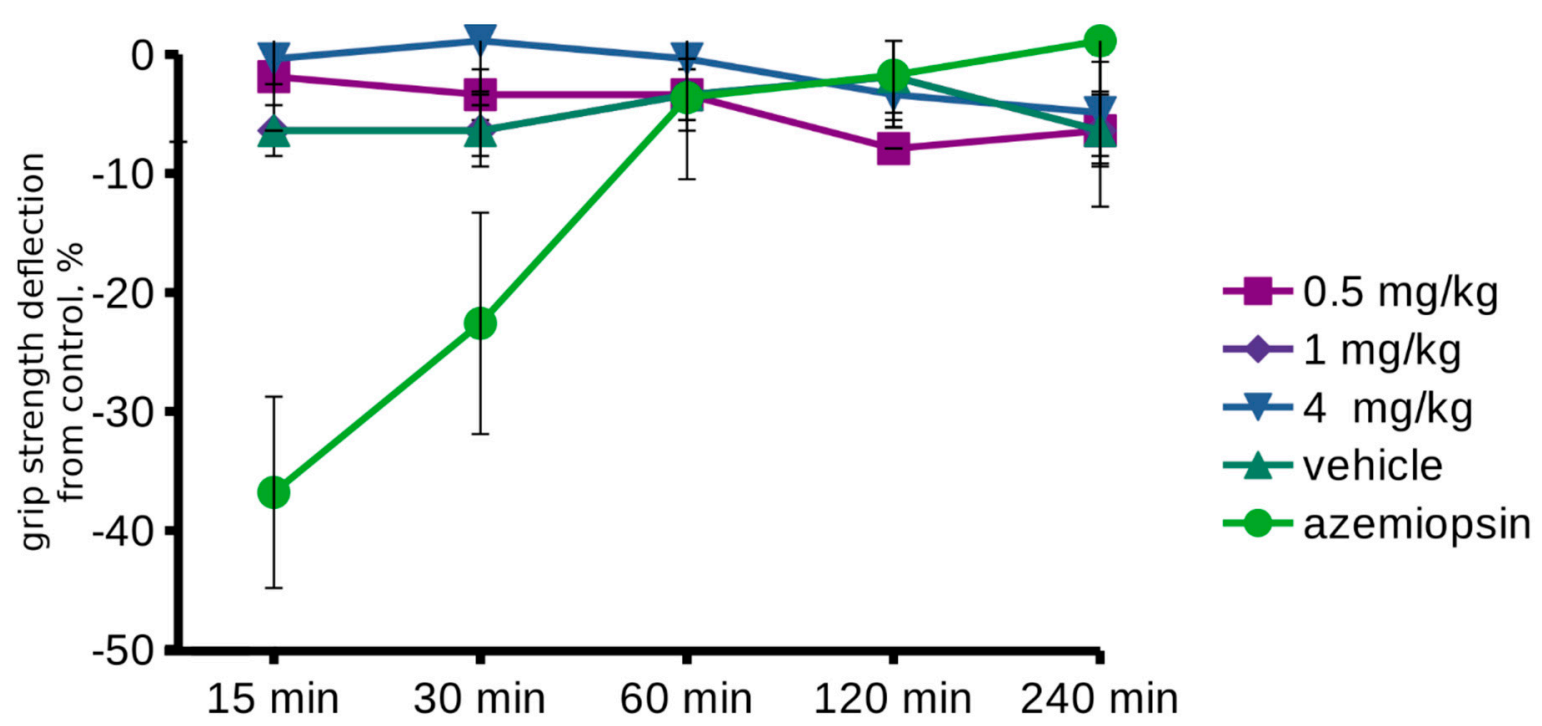

Figure 4. Evaluation of the AA-CHOL muscle relaxant activity in mice grip strength measurements. AA-CHOL intramuscular injection in various doses does not produce a significant muscle relaxation. In contrast, azemiopsin at $0.1 \mathrm{mg} / \mathrm{kg}$ shows significant (ANOVA, $p<0.05$ ) muscle relaxation (green line, circles) at 15 and $30 \mathrm{~min}$.

\subsection{Acylcholines Inhibit the Viability of A549 Cells}

Lung cancer cells endogenously express $\alpha 7 \mathrm{nAChR}$, and their activation on these cells leads to stimulation of proliferation [29]. Because acylcholines demonstrated the ability to inhibit nAChR, we hypothesized that they could inhibit proliferation of a lung cancer cell line A549. Indeed, Ol-CHOL dose-dependently decreased A549 viability after a $24 \mathrm{~h}$ incubation, reaching $45 \%$ inhibition at the concentration of $100 \mu \mathrm{M}$. Ln-CHOL and AA-CHOL produced only a $10 \%$ decrease at the $100 \mu \mathrm{M}$ concentration, while DHA-CHOL was inactive (Figure 5A). The treatment with Ol-CHOL was accompanied by phosphatidylserine exposure on the membrane, caspase 9 and caspase 3, but not caspase 8 activation (Figure 5B,C), thus, indicating apoptosis induction. 


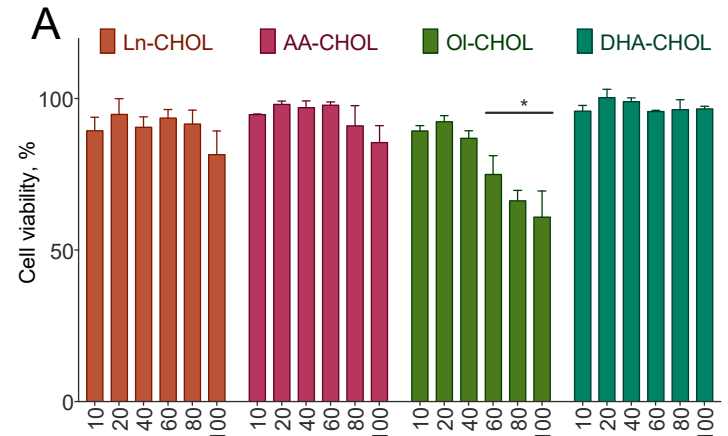

[Substance], $\mu \mathrm{M}$

C

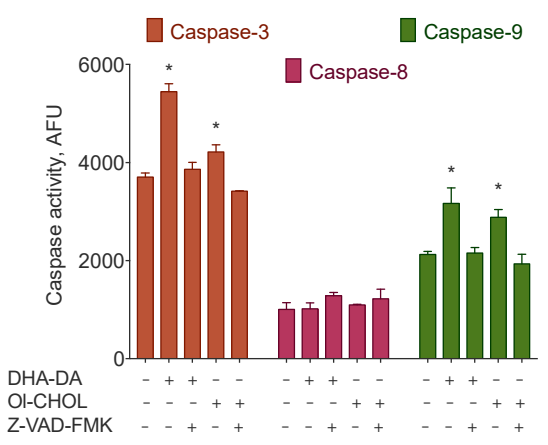

B

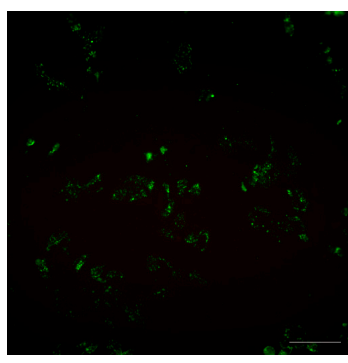

Control

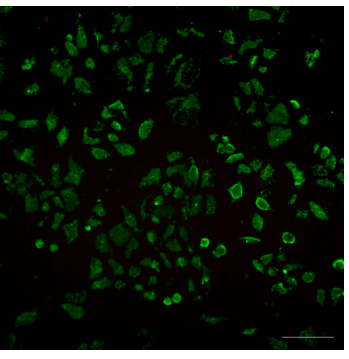

$\mathrm{OI-CHOL}$

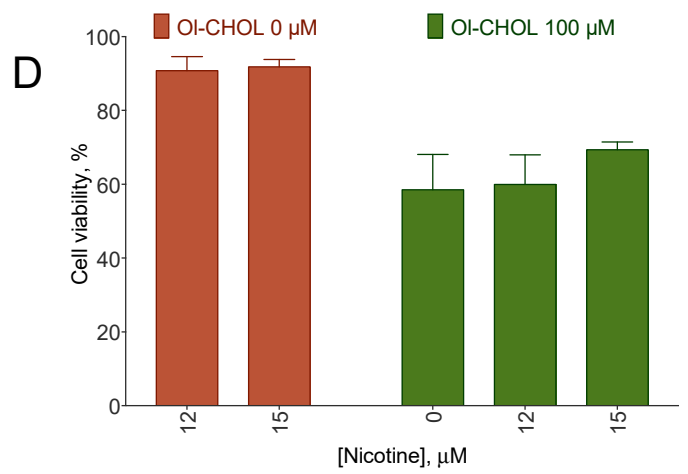

Figure 5. A549 lung cancer cell line viability inhibition by acylcholines. The cells were incubated with the substances for $24 \mathrm{~h}$. Cell viability was determined using an MTT test. (A) the cytotoxicity of acylcholines. In the ANOVA with the Tukey post-hoc test, the survival of the cells at the Ol-CHOL concentration $100 \mu \mathrm{M}$ differed statistically significant from other acylcholines with $p<0.05$. Mean \pm standard deviation, $\mathrm{N}=3$ experiments; (B) Apoptosis induction by $150 \mu \mathrm{M}$ of Ol-CHOL, green phosphatidylserine sensor fluorescence, red membrane-impermeable nucleus stain 7-AAD, fluorescence microscopy, scale bar is $100 \mu \mathrm{m}$; (C) Caspase activation after $5 \mathrm{~h}$ incubation with either $100 \mu \mathrm{M}$ of $\mathrm{N}$-docosahexaenoyl dopamine (DHA-DA, positive control) or $150 \mu \mathrm{M}$ of Ol-CHOL with or without $100 \mu \mathrm{M}$ of the pan-caspase inhibitor Z-VAD-FMK, fluorescence of hydrolyzed specific substrates Ac-DEVD-AFC (Caspase 3), Ac-LEHD-AFC (Caspase 9), and SCP0139 (Caspase 8). Mean \pm standard deviation, $\mathrm{N}=3$ experiments. ${ }^{*}$, a statistically significant difference from the untreated control; (D) the cytotoxicity of Ol-CHOL in the presence of nicotine. Mean \pm standard deviation, $\mathrm{N}=3$ experiments.

On the one hand, the specific blocker of $\mathrm{AAChR}$ methyllycaconitine did not affect A549 proliferation up to the concentration of $10 \mu \mathrm{M}$. Nicotine, on the other hand, slightly decreased A549 proliferation at the concentration $15 \mu \mathrm{M}$ but did not affect the cytotoxicity of 90 or $100 \mu \mathrm{M}$ of Ol-CHOL (Figure 5D).

\subsection{Acylcholines Inhibit the Activity of Cholinesterases}

Because long-chain acylcholines are structurally similar to the acetylcholine, we hypothesized that the enzymes which metabolize the latter could also degrade the long-chain acylcholines. We tested the ability of purified AChE and BChE to hydrolyze AA-CHOL. ATCh, as ACh analogue for spectrophotometric Ellman assay was used as a control for the enzyme activity, and incubations with the heat-inactivated enzyme were used for non-enzymatic degradation controls. Under experimental conditions, ATCh was fully hydrolyzed by both enzymes. AA-CHOL was not hydrolyzed by AChE, but with BChE the hydrolysis of arachidonoylcholine accounted for up to $30 \%$ during $40 \mathrm{~min}$. With the heat-inactivated enzymes, no hydrolysis of either ATCh or AA-CHOL was detected.

To further check if acylcholines possess the ability to interact with these enzymes, we tested their inhibition of AChE and BChE catalyzed ATCh hydrolysis (Table 3). Only AA-CHOL was active in these experiments, although the obtained $\mathrm{IC}_{50}$ values were quite high. 
Table 3. Acylcholines inhibition of ATCh hydrolysis by acetylcholine degrading enzymes AChE and BChE.

\begin{tabular}{ccc}
\hline \multirow{2}{*}{ Substance } & AChE & BChE \\
\cline { 2 - 3 } & \multicolumn{2}{c}{$\mathbf{I C}_{\mathbf{5 0}, \boldsymbol{\mu M}}{ }^{*}$} \\
\hline AA-CHOL & $90 \pm 1$ & $170 \pm 16$ \\
\hline Ln-CHOL & $>300$ & $>300$ \\
\hline DHA-CHOL & $>300$ & $>300$ \\
\hline$*$ Mean \pm standard deviation, N=11 experiments
\end{tabular}

* Mean \pm standard deviation, $\mathrm{N}=11$ experiments.

The graphical analysis of steady-state inhibition kinetics data for AA-CHOL toward AChE and BChE is shown in Figure 6. Binding of AA-CHOL to AChE and BChE changed both $V_{\max }$ and $K_{\mathrm{m}}$ values. Such alterations are consistent with mixed-type inhibition (Figure 6). For AChE inhibition $K_{i}=16.7 \pm 1.5 \mu \mathrm{M}$ and $\alpha K_{i}=51.4 \pm 4.1 \mu \mathrm{M}$, for BChE inhibition $K_{i}=70.5 \pm 6.3 \mu \mathrm{M}$ and $\alpha K_{i}=214 \pm 17 \mu \mathrm{M}$.

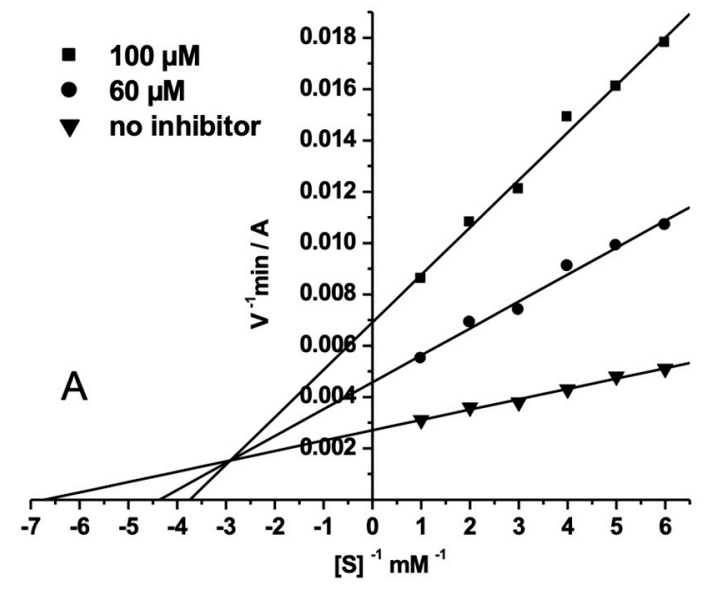

A

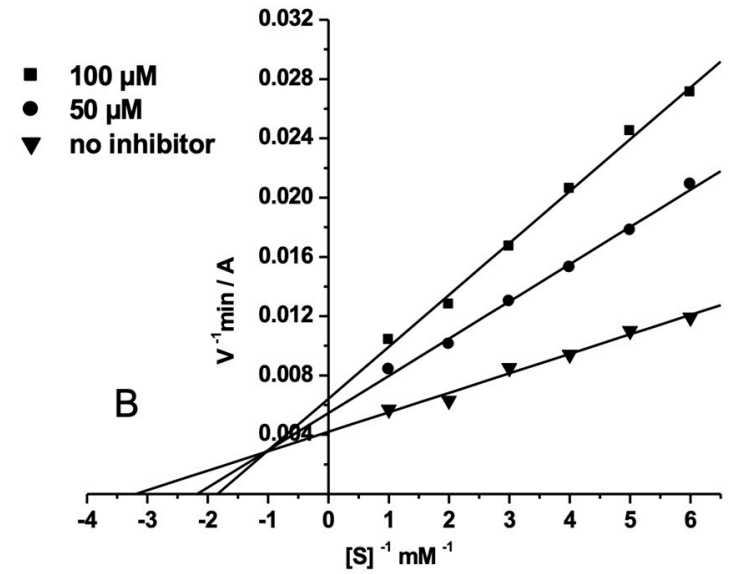

B

Figure 6. Lineweaver-Burk plots for steady state inhibition of AChE (A) and BChE (B) by AA-CHOL.

According to the molecular docking results, choline moiety of AA-CHOL was found in the AChE active site, binding to the cation-binding pocket, but carbonyl oxygen atom of the ester group was outside the oxyanion hole due to a large size of acyl chain, which makes hydrolysis reaction unlikely (Figure 7A). Arachidonic chain spans through the gorge and enters the AChE peripheral anionic site (PAS, separated by Y124 and Y341). In addition, docked poses of AA-CHOL were obtained in PAS only, which is consistent with mixed-type inhibition. BChE has a larger acyl-binding pocket and wider gorge, which binds the carbonyl oxygen atom of the ester group to the oxyanion hole. This makes the hydrolysis reaction possible (Figure 7B) and agrees with the experimental data. There were additional binding poses of AA-CHOL outside the active site, which was consistent with a mixed-type inhibition observed experimentally. Arachidonic chain was found bent in the lower part of the gorge; such difference in the binding mode of ligands with lengthy chains to $\mathrm{AChE}$ and $\mathrm{BChE}$ is quite typical due to the difference of the gorge radii $[30,31]$. 


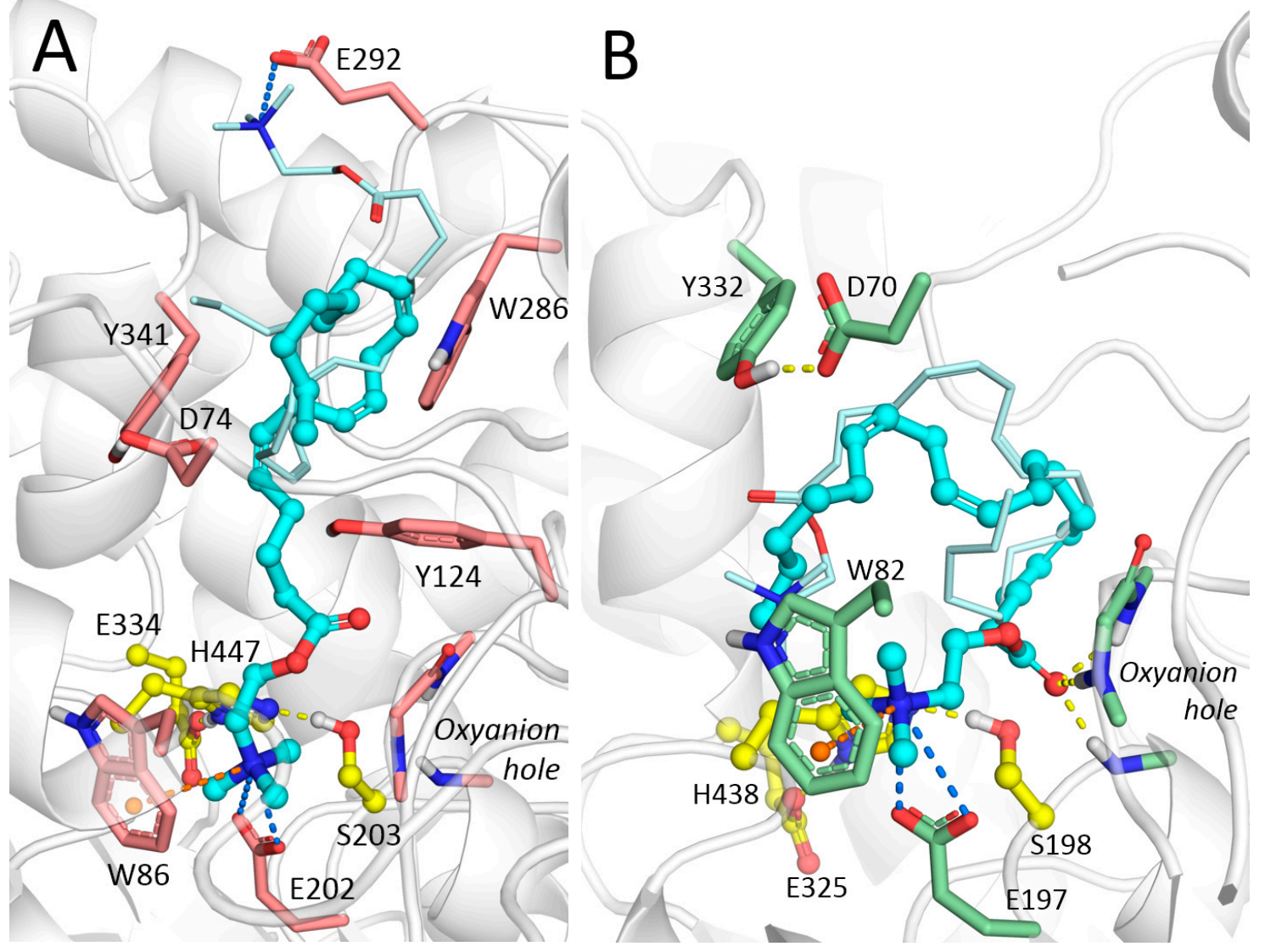

Figure 7. Docked poses of AA-CHOL inside (A) AChE and (B) BChE gorges. The best binding pose of AA-CHOL is shown with balls and sticks, carbon atoms colored cyan, poses in the PAS (for AChE) and outside active site (for BChE) are shown with lines, carbon atoms colored pale cyan.

\section{Discussion}

Cholines acylated with unsaturated fatty acids are a recently discovered family of endogenous lipids. While fatty acid derivatives of other neurotransmitters possess interesting neuro- and immunomodulatory properties, the data on the biological activity of acylcholines remain very limited. On the basis of the structure similarity, we hypothesized that the receptor targets and metabolizing enzymes for long-chain unsaturated acylcholines could be similar to those interacting with acetylcholine. To test this assumption, we studied four long-chain unsaturated acylcholines containing residues of arachidonic, oleic, linoleic, and docosahexaenoic acids in the $\mathrm{nAChR}$ binding, $\mathrm{nAChR}$ functional response and in the interaction with the ACh degrading enzymes. Indeed, we found that long-chain unsaturated acylcholines can interact with the ACh targets; in all cases, an inhibitory activity or receptor interaction was observed.

The acylcholines were chemically synthesized via the intermediate acyldimethylaminoethanols, as in [13]. The synthesis and purification procedure was quite straightforward, and the reaction yields were typical for the syntheses of the acylated neurotransmitters [32,33].

The first step was to test whether the long-chain unsaturated acylcholines interact with the acetylcholine-binding site of the $\mathrm{nAChR}$. We chose the following three standard models for this task: L. stagnalis AChBP, T. californica muscle-type $\mathrm{nAChR}$, and human neuronal $\alpha 7 \mathrm{nAChR}$. The existing literature contains no data on long-chain acylcholine binding to AChRs, except for the data on allosteric binding of phosphocholine and phosphatidylcholine [34]. The efficiency of acylcholines association with the AChBP was almost the same as compared with the ACh binding, whereas, with the two nAChR subtypes, the efficiency was two to four times weaker. DHA-CHOL was virtually inactive in the competition experiments on the nAChRs, while more active ones were the less unsaturated acylcholines. A problem in the binding analysis of such molecules could be their possible detergent activity, as they 
possess both a hydrophobic tail and a charged head. However, a classical detergent sodium dodecyl sulfate at a concentration of up to $40 \mu \mathrm{M}$ did not inhibit $\alpha$-bungarotoxin binding in our setting, and so this activity could be ruled out. The fact that the extension of the acid residue significantly decreased binding to the nAChRs, but not to the AChBP (lacking the membrane environment), could be possibly explained by the sequestration of the acylcholines with the membrane lipids surrounding of the receptor. To test this, we calculated a measure for substances hydrophobicity, namely the logarithms of partition coefficient octanol-water using the ChemBioDraw 12 software. The obtained results (4.03, 4.51, 4.12, and 4.21 for Ln-CHOL, OL-CHOL, AA-CHOL, and DHA-CHOL, respectively) were in the range typical for other lipids that readily associate with membranes, e.g., sphingosine (logP 4.88), and thus agreed with this hypothesis.

To study the functional response to the acylcholines, we measured their ability to induce $\mathrm{Ca}^{2+}$ mobilization in the SH-SY5Y cells, which endogenously express $\alpha 7$ and some other nAChRs [35]. The effect on the $\alpha 7 \mathrm{nAChR}$ in these cells can be discerned only in the presence of PNU120596, a positive allosteric modulator (PAM) of this nAChR subtype. None of the tested compounds showed agonistic properties under these conditions. However, in the presence of PNU120596, the tested compounds with similar potency inhibited the acetylcholine-evoked $\mathrm{Ca}^{2+}$ rise in a concentration-dependent manner. We discovered such an inhibitory activity for the long-chain unsaturated acylcholines for the first time, while shorter acylcholines (like palmitoylcholine) are known to act as nAChR-like agonists in physiological tests [4]. The binding site in the nAChRs is located inside the cavity under the C-loop [36]. The specific geometric fit of a ligand to the site is needed to activate the receptor [37]. Fatty acid chain elongation could, in principle, disrupt the ligand fit to the site and convert an agonist to an antagonist. Such an effect could be the reason for the observed nAChR-blocking activity of long-chain unsaturated acylcholines.

A somewhat contradictory activity has been earlier described for AA-CHOL and DHA-CHOL on the unfertilized sea urchin eggs, which expressed receptors somewhat similar to the nAChRs [12]. In this model, AA-CHOL and DHA-CHOL dose-dependently induced the larva immobilization and cell lysis, and the noncompetitive nicotinic cholinergic antagonist QX-222 antagonized this effect [13]. Thus, AA-CHOL acted as a nAChR agonist or a cholinomimetic in this model. This discrepancy in the activity could be due to a possible significant difference between the mammalian and sea urchin AChRs. The latter could be more similar to the muscarinic ACh receptor (mAChR) [38], which has a different active site structure and an allosteric regulation site on the receptor surface [39].

Distinct nAChR subtypes are involved in the stimulation of cancer cell proliferation [40]. Because the tested acylcholines appeared to be the nAChR blockers, we analyzed their activity on the A549 lung cancer cells which endogenously express $\alpha 7 \mathrm{nAChR}$ [41]. Ol-CHOL, Ln-CHOL, and AA-CHOL, but not DHA-CHOL, dose-dependently decreased the A549 viability after a $24 \mathrm{~h}$ incubation, the first compound being the most active. The activity of acylcholines in this experimental setting correlated with the data on their receptor binding, and thus the action via ACh receptor seems highly probable. According to the literature data, the selective antagonist of $\mathrm{nAChR}$ methyllycaconitine at high concentrations $(1$ to $10 \mu \mathrm{M})$ inhibits the proliferation of the A549 cells. However, this effect is relatively small and manifests itself predominantly after 48 and $72 \mathrm{~h}$ of incubation [42]. Considering much lower affinity of acylcholines for $\mathrm{nAChR}$, as compared with methyllycaconitine, their cytotoxicity might not arise solely from the $n A C h R$ inhibition. A plausible hypothesis could be the concomitant activation of $\mathrm{mAChRs}$ by acylcholines, as the blocking of M2 mAChR on A549 cells was shown to inhibit their proliferation [43], or a combined action via both receptor types.

With regards to the in vitro tests, the acylcholines behaved as nAChR blockers, and we supposed that they could also act as neuromuscular blocking myorelaxants in vivo. It is noteworthy that such activity was recently demonstrated for azemiopsin, a linear peptide from the snake venom inhibiting the muscle $\mathrm{nAChR}$ at micromolar concentrations $[28,44]$. However, AA-CHOL showed no difference from the control in mouse grip strength test after the intramuscular injection. There could be several explanations for this fact including: insufficiency of either dose or time, substance degradation by the 
local enzymes, and problems with substance diffusion. An insufficient dose or time could be ruled out, as there was no substance activity even after a $30 \mathrm{mg} / \mathrm{kg}$ injection and $240 \mathrm{~min}$ of observation. In comparison, azemiopsin produced a relaxant effect in the concentration range 30-300 $\mu \mathrm{g} / \mathrm{kg}, 10 \mathrm{~min}$ after injection [28]. Substance degradation is also of low probability, as we did not observe acylcholines hydrolysis by $\mathrm{AChE}$ and only a very negligible degradation by BChE. Problems with substance diffusion are possible, as studied acylcholines are quite hydrophobic. However, AA-CHOL and its long-chain analogs tested in our experiments are endogenous compounds, and their even very low activity as muscle relaxants could be of physiological relevance.

In addition to the action on the $\mathrm{nAChR}$, we tested the acylcholines activity on another part of the acetylcholine signaling system, namely on the acetylcholine hydrolyzing enzymes. AChE did not hydrolyze the tested acylcholines, but AA-CHOL inhibited its activity as a mixed-type inhibitor with quite high inhibition constants, which agrees with molecular docking results. Neither Ln-CHOL nor DHA-CHOL had noticeable inhibitory activity. BChE was also rather weakly inhibited by AA-CHOL. Molecular docking confirmed the possibility of BChE catalyzed hydrolysis of AA-CHOL and mixed-type mechanism of its inhibition of ATCh hydrolysis. No data on the inhibition of the $\mathrm{AChE}$ and BChE by acylcholines could be found in the literature. The existence of other enzymes for degradation of acylcholines seems possible, but testing this hypothesis requires further studies.

Therefore, long-chain fatty acid derivatives of choline could be both inhibitors (via the receptor blocking) and weak potentiators (via the inhibition of acetylcholine hydrolysis) of the acetylcholine signaling. However, receptor inhibition appeared at concentrations in the range 10-50 $\mu \mathrm{M}$, while enzyme inhibition required 100 to $300 \mu \mathrm{M}$ of the substances. Thus, receptor blocking and acetylcholine signaling inhibition appear as a dominating activity of acylcholines. At present, there are no data on the concentrations and biosynthesis of these compounds, making the correct estimation of their biological role very difficult. The discovered cytotoxicity of Ol-CHOL against the lung cancer cell line A549 points to the existence of additional receptor targets for this substance, and clarification of this issue could be of interest.

\section{Conclusion}

For the first time, we have demonstrated that arachidonoylcholine and its unsaturated fatty acid analogs with the chain length of 18 and 22 carbon atoms are inhibitors of the neuronal and muscle-type nicotinic acetylcholine receptors and modest inhibitors of $\mathrm{AChE}$ and $\mathrm{BChE}$, thus, playing a possible role as endogenous modulators of the acetylcholine signaling system.

Supplementary Materials: The following are available online at http://www.mdpi.com/2218-273X/10/2/283/s1, Figure S1: Purity check of AA-CHOL. HPLC data. Column ProntoSil 120-5-C18 AQ; gradient elution with 0.1\% trifluoroacetic acid in acetonitrile/ $\mathrm{H}_{2} \mathrm{O}$. Peak 1 is the target compound. Calculated compound purity is $99.4 \%$, Figure S2: Purity check of Ol-CHOL. HPLC data. Column ProntoSil 120-5-C18 AQ; gradient elution with 0.1\% trifluoroacetic acid in acetonitrile/ $\mathrm{H}_{2} \mathrm{O}$. Calculated compound purity is $98.7 \%$, Figure S3: Purity check of Ln-CHOL. HPLC data. Column ProntoSil 120-5-C18 AQ; gradient elution with 0.1\% trifluoroacetic acid in acetonitrile/ $\mathrm{H}_{2} \mathrm{O}$. Calculated compound purity is $99.4 \%$, Figure S4: Purity check of DHA-CHOL. HPLC data. Column ProntoSil $120-5-\mathrm{C} 18 \mathrm{AQ}$; gradient elution with $0.1 \%$ trifluoroacetic acid in acetonitrile/ $\mathrm{H}_{2} \mathrm{O}$. Calculated compound purity is $97.9 \%$, Figure S5: GABA-evoked currents in Xenopus oocyte expressing murine $\alpha 1 \beta 3 \gamma 2$ GABAA receptor: control (blue line) and under $10 \mu \mathrm{M}$ AA-Chol treatment. AA-Chol was pre-applied 5 min before GABA and was added to GABA solution during the application. Current amplitude does not show significant difference from the control $(99+6 \%, n=3, p<0.05$, Student's t-test).

Author Contributions: D.S.K. designed and performed the two-electrode voltage clamp and Ca ${ }^{2+}$ mobilization assay; E.V.K. did radioligand assay; M.G.A. designed and performed cytotoxicity and apoptosis staining assays and wrote the text; E.V.F.-A. and S.S.Z. performed cytotoxicity and caspase activation assays; G.N.Z., N.M.G, and I.V.S. synthesized the compounds; G.F.M. and N.V.K. designed and performed enzyme inhibition assays; N.P.B. and O.G.S. designed and performed enzyme kinetics and mechanism experiment; S.V.L. and G.F.M. designed and performed computer modeling; V.A.P., Y.P., and I.A.D. designed and performed animal experiments; V.V.B., I.E.K., and V.I.T. planned the project, discussed work and corrected the text. All authors have read and agreed to the published version of the manuscript.

Funding: D.S.K. was supported by the RSF grant 18-74-10088. V.I.T. was supported by the RSF grant 16-14-00215 p. The study on A549 and SH-SY5Y cells was performed within the framework of the State task IBCH RAS 2019 
(\#0101-2019-0031). The enzymes inhibition and kinetic study were performed within the framework of the State task IPAC RAS 2019 (\# 0090-2019-0005).

Acknowledgments: The authors are grateful to Prof. Sulan Luo (Key Laboratory for Marine Drugs of Haikou, Hainan University, China) for AChBP, to F. Hucho (Free University of Berlin, Berlin, Germany) for nAChR-enriched membranes from T. californica, to Veit Witzemann (Department of Molecular Neurobiology, Max Planck Institute for Medical Research, Heidelberg, Germany) for muscle nAChR clones, and to EliLilly (London, UK) for GH4C1 cells transfected with human $\alpha 7 \mathrm{nAChR}$. Computer modeling was carried out using equipment from the shared research facilities of the HPC computing resources at Lomonosov Moscow State University [45].

Conflicts of Interest: The authors declare no conflict of interest.

\section{References}

1. Campoy, F.J.; Vidal, C.J.; Muñoz-Delgado, E.; Montenegro, M.F.; Cabezas-Herrera, J.; Nieto-Cerón, S. Cholinergic system and cell proliferation. Chem. Biol. Interact. 2016, 259, 257-265. [CrossRef] [PubMed]

2. Wessler, I.; Kirkpatrick, C.J. Acetylcholine beyond neurons: The non-neuronal cholinergic system in humans. Br. J. Pharmacol. 2008, 154, 1558-1571. [CrossRef] [PubMed]

3. Rossier, J. Acetyl coenzyme A and coenzyme A analogues. Their effects on rat brain choline acetyltransferase. Biochem. J. 1977, 165, 321-326. [CrossRef] [PubMed]

4. Hunt, R.; de Mortemer Taveau, R. The Effects of a Number of Derivatives of Choline and Analogous Compounds on the Blood-pressure; US Government Printing Office: Washington, DC, USA, 1911.

5. Root, W.S.; Hofmann, F.G. The Nervous System: Autonomic Nervous System Drugs; Academic Press: New York, NY, USA, 1967.

6. Moreno, S.; Gerbig, S.; Schulz, S.; Spengler, B.; Diener, M.; Bader, S. Epithelial propionyl- and butyrylcholine as novel regulators of colonic ion transport. Br. J. Pharmacol. 2016, 173, 2766-2779. [CrossRef] [PubMed]

7. Zarei, I.; C Oppel, R.; C Borresen, E.; J Brown, R.; P Ryan, E. Modulation of plasma and urine metabolome in colorectal cancer survivors consuming rice bran. Integr. Food, Nutr. Metab. 2019, 6. [CrossRef] [PubMed]

8. Vorkas, P.A.; Isaac, G.; Anwar, M.A.; Davies, A.H.; Want, E.J.; Nicholson, J.K.; Holmes, E. Untargeted UPLC-MS profiling pipeline to expand tissue metabolome coverage: Application to cardiovascular disease. Anal. Chem. 2015, 87, 4184-4193. [CrossRef]

9. Vorkas, P.A.; Shalhoub, J.; Isaac, G.; Want, E.J.; Nicholson, J.K.; Holmes, E.; Davies, A.H. Metabolic phenotyping of atherosclerotic plaques reveals latent associations between free cholesterol and ceramide metabolism in atherogenesis. J. Proteome Res. 2015, 14, 1389-1399. [CrossRef]

10. Zeleznik, O.A.; Poole, E.M.; Lindstrom, S.; Kraft, P.; Van Hylckama Vlieg, A.; Lasky-Su, J.A.; Harrington, L.B.; Hagan, K.; Kim, J.; Parry, B.A.; et al. Metabolomic analysis of 92 pulmonary embolism patients from a nested case-control study identifies metabolites associated with adverse clinical outcomes. J. Thromb. Haemost. 2018, 16, 500-507. [CrossRef]

11. Leung, R.Y.H.; Li, G.H.Y.; Cheung, B.M.Y.; Tan, K.C.B.; Kung, A.W.C.; Cheung, C.-L. Serum metabolomic profiling and its association with 25-hydroxyvitamin D. Clin. Nutr. 2019. [CrossRef]

12. Ivonnet, P.I.; Chambers, E.L. Nicotinic acetylcholine receptors of the neuronal type occur in the plasma membrane of sea urchin eggs. Zygote 1997, 5, 277-287. [CrossRef]

13. Bezuglov, V.V.; Zinchenko, G.N.; Nikitina, L.A.; Buznikov, G.A. Arachidonoylcholine and O-arachidonoyldimethylaminoethanol as new cholinergic substances. Russ J Bioorg Chem 2001, 207, 200-203. [CrossRef] [PubMed]

14. van de Loosdrecht, A.A.; Beelen, R.H.J.; Ossenkoppele, G.J.; Broekhoven, M.G.; Langenhuijsen, M.M.A.C. A tetrazolium-based colorimetric MTT assay to quantitate human monocyte mediated cytotoxicity against leukemic cells from cell lines and patients with acute myeloid leukemia. J. Immunol. Methods 1994, 174, 311-320. [CrossRef]

15. Ellman, G.L.; Courtney, K.D.; Andres, V.; Featherstone, R.M. A new and rapid colorimetric determination of acetylcholinesterase activity. Biochem. Pharmacol. 1961, 7, 88-95. [CrossRef]

16. Makhaeva, G.F.; Boltneva, N.P.; Lushchekina, S.V.; Serebryakova, O.G.; Stupina, T.S.; Terentiev, A.A.; Serkov, I.V.; Proshin, A.N.; Bachurin, S.O.; Richardson, R.J. Synthesis, molecular docking and biological evaluation of $\mathrm{N}, \mathrm{N}$-disubstituted 2-aminothiazolines as a new class of butyrylcholinesterase and carboxylesterase inhibitors. Bioorg. Med. Chem. 2016, 24, 1050-1062. [CrossRef] [PubMed] 
17. Schmidt, M.W.; Baldridge, K.K.; Boatz, J.A.; Elbert, S.T.; Gordon, M.S.; Jensen, J.H.; Koseki, S.; Matsunaga, N.; Nguyen, K.A.; Su, S.; et al. General atomic and molecular electronic structure system. J. Comput. Chem. 1993, 14, 1347-1363. [CrossRef]

18. Lushchekina, S.V.; Makhaeva, G.F.; Novichkova, D.A.; Zueva, I.V.; Kovaleva, N.V.; Richardson, R.R. Supercomputer Modeling of Dual-Site Acetylcholinesterase (AChE) Inhibition. Supercomput. Front. Innov. 2018, 5, 89-97.

19. Cheung, J.; Rudolph, M.J.; Burshteyn, F.; Cassidy, M.S.; Gary, E.N.; Love, J.; Franklin, M.C.; Height, J.J. Structures of Human Acetylcholinesterase in Complex with Pharmacologically Important Ligands. J. Med. Chem. 2012, 55, 10282-10286. [CrossRef]

20. Nicolet, Y.; Lockridge, O.; Masson, P.; Fontecilla-Camps, J.C.; Nachon, F. Crystal Structure of Human Butyrylcholinesterase and of Its Complexes with Substrate and Products. J. Biol. Chem. 2003, 278, 41141-41147. [CrossRef]

21. Masson, P.; Lushchekina, S.; Schopfer, L.M.; Lockridge, O. Effects of viscosity and osmotic stress on the reaction of human butyrylcholinesterase with cresyl saligenin phosphate, a toxicant related to aerotoxic syndrome: Kinetic and molecular dynamics studies. Biochem. J. 2013, 454, 387-399. [CrossRef]

22. Morris, G.M.; Huey, R.; Lindstrom, W.; Sanner, M.F.; Belew, R.K.; Goodsell, D.S.; Olson, A.J. AutoDock4 and AutoDockTools4: Automated docking with selective receptor flexibility. J. Comput. Chem. 2009, 30, 2785-2791. [CrossRef]

23. Morris, G.M.; Goodsell, D.S.; Halliday, R.S.; Huey, R.; Hart, W.E.; Belew, R.K.; Olson, A.J. Automated docking using a Lamarckian genetic algorithm and an empirical binding free energy function. J. Comput. Chem. 1998, 19, 1639-1662. [CrossRef]

24. Smit, A.B.; Syed, N.I.; Schaap, D.; van Minnen, J.; Klumperman, J.; Kits, K.S.; Lodder, H.; van der Schors, R.C.; van Elk, R.; Sorgedrager, B.; et al. A glia-derived acetylcholine-binding protein that modulates synaptic transmission. Nature 2001, 411, 261-268. [CrossRef] [PubMed]

25. Brams, M.; Pandya, A.; Kuzmin, D.; van Elk, R.; Krijnen, L.; Yakel, J.L.; Tsetlin, V.; Smit, A.B.; Ulens, C. A structural and mutagenic blueprint for molecular recognition of strychnine and d-tubocurarine by different cys-loop receptors. PLoS Biol. 2011, 9, e1001034. [CrossRef] [PubMed]

26. Rucktooa, P.; Smit, A.B.; Sixma, T.K. Insight in $\mathrm{AChR}$ subtype selectivity from AChBP crystal structures. Biochem. Pharmacol. 2009, 78, 777-787. [CrossRef] [PubMed]

27. Kudryavtsev, D.S.; Shelukhina, I.V.; Son, L.V.; Ojomoko, L.O.; Kryukova, E.V.; Lyukmanova, E.N.; Zhmak, M.N.; Dolgikh, D.A.; Ivanov, I.A.; Kasheverov, I.E.; et al. Neurotoxins from snake venoms and $\alpha$-conotoxin ImI inhibit functionally active ionotropic $\gamma$-aminobutyric acid (GABA) receptors. J. Biol. Chem. 2015, 290, 22747-22758. [CrossRef]

28. Shelukhina, I.V.; Zhmak, M.N.; Lobanov, A.V.; Ivanov, I.A.; Garifulina, A.I.; Kravchenko, I.N.; Rasskazova, E.A.; Salmova, M.A.; Tukhovskaya, E.A.; Rykov, V.A.; et al. Azemiopsin, a selective peptide antagonist of muscle nicotinic acetylcholine receptor: Preclinical evaluation as a local muscle relaxant. Toxins (Basel). 2018, 10. [CrossRef]

29. Wang, S.; Hu, Y. $\alpha 7$ nicotinic acetylcholine receptors in lung cancer (Review). Oncol. Lett. 2018, 16, 1375-1382. [CrossRef]

30. Makhaeva, G.F.; Kovaleva, N.V.; Boltneva, N.P.; Lushchekina, S.V.; Rudakova, E.V.; Stupina, T.S.; Terentiev, A.A.; Serkov, I.V.; Proshin, A.N.; Radchenko, E.V.; et al. Conjugates of tacrine and 1,2,4-thiadiazole derivatives as new potential multifunctional agents for Alzheimer's disease treatment: Synthesis, quantum-chemical characterization, molecular docking, and biological evaluation. Bioorg. Chem. 2020, 94, 103387. [CrossRef]

31. Makhaeva, G.F.; Shevtsova, E.F.; Boltneva, N.P.; Lushchekina, S.V.; Kovaleva, N.V.; Rudakova, E.V.; Bachurin, S.O.; Richardson, R.J. Overview of novel multifunctional agents based on conjugates of $\gamma$-carbolines, carbazoles, tetrahydrocarbazoles, phenothiazines, and aminoadamantanes for treatment of Alzheimer's disease. Chem. Biol. Interact. 2019, 308, 224-234. [CrossRef]

32. Akimov, M.G.; Gretskaya, N.M.; Karnoukhova, V.A.; Serkov, I.V.; Proshin, A.N.; Shtratnikova, V.Y.; Bezuglov, V.V. The effect of docosahexaenoic acid moiety on the cytotoxic activity of 1,2,4-thiadiazole derivatives. Biochem. Suppl. Ser. B Biomed. Chem. 2014, 8, 43-46. [CrossRef]

33. Bisogno, T.; Melck, D.; Bobrov, M.Y.; Gretskaya, N.M.; Bezuglov, V.V.; De Petrocellis, L.; Di Marzo, V. N-acyl-dopamines: Novel synthetic CB1 cannabinoid-receptor ligands and inhibitors of anandamide 
inactivation with cannabimimetic activity in vitro and in vivo. Biochem. J. 2000, 351, 817-824. [CrossRef] [PubMed]

34. Zakrzewicz, A.; Richter, K.; Agné, A.; Wilker, S.; Siebers, K.; Fink, B.; Krasteva-Christ, G.; Althaus, M.; Padberg, W.; Hone, A.J.; et al. Canonical and Novel Non-Canonical Cholinergic Agonists Inhibit ATP-Induced Release of Monocytic Interleukin-1 $\beta$ via Different Combinations of Nicotinic Acetylcholine Receptor Subunits $\alpha 7, \alpha 9$ and $\alpha 10$. Front. Cell. Neurosci. 2017, 11, 189. [CrossRef] [PubMed]

35. Peng, X.; Gerzanich, V.; Anand, R.; Wang, F.; Lindstrom, J. Chronic nicotine treatment up-regulates alpha3 and alpha7 acetylcholine receptor subtypes expressed by the human neuroblastoma cell line SH-SY5Y. Mol. Pharmacol. 1997, 51, 776-784. [CrossRef] [PubMed]

36. Clementi, F.; Fornasari, D.; Gotti, C. Neuronal nicotinic receptors, important new players in brain function. Eur. J. Pharmacol. 2000, 393, 3-10. [CrossRef]

37. Tripathy, S.; Zheng, W.; Auerbach, A. A single molecular distance predicts agonist binding energy in nicotinic receptors. J. Gen. Physiol. 2019, 151, 452-464. [CrossRef] [PubMed]

38. Harrison, P.K.; Falugi, C.; Angelini, C.; Whitaker, M.J. Muscarinic signalling affects intracellular calcium concentration during the first cell cycle of sea urchin embryos. Cell Calcium 2002, 31, 289-297. [CrossRef]

39. Kruse, A.C.; Kobilka, B.K.; Gautam, D.; Sexton, P.M.; Christopoulos, A.; Wess, J. Muscarinic acetylcholine receptors: Novel opportunities for drug development. Nat. Rev. Drug Discov. 2014, 13, 549-560. [CrossRef]

40. Egleton, R.D.; Brown, K.C.; Dasgupta, P. Nicotinic acetylcholine receptors in cancer: Multiple roles in proliferation and inhibition of apoptosis. Trends Pharmacol. Sci. 2008, 29, 151-158. [CrossRef]

41. Mucchietto, V.; Fasoli, F.; Pucci, S.; Moretti, M.; Benfante, R.; Maroli, A.; Di Lascio, S.; Bolchi, C.; Pallavicini, M.; Dowell, C.; et al. $\alpha 9$ - and $\alpha 7$-containing receptors mediate the pro-proliferative effects of nicotine in the A549 adenocarcinoma cell line. Br. J. Pharmacol. 2018, 175, 1957-1972. [CrossRef]

42. Yan, Y.; Su, C.; Hang, M.; Huang, H.; Zhao, Y.; Shao, X.; Bu, X. Recombinant Newcastle disease virus rL-RVG enhances the apoptosis and inhibits the migration of A549 lung adenocarcinoma cells via regulating alpha 7 nicotinic acetylcholine receptors in vitro. Virol. J. 2017, 14, 190. [CrossRef]

43. Zhao, Q.; Gu, X.; Zhang, C.; Lu, Q.; Chen, H.; Xu, L. Blocking M2 muscarinic receptor signaling inhibits tumor growth and reverses epithelial-mesenchymal transition (EMT) in non-small cell lung cancer (NSCLC). Cancer Biol. Ther. 2015, 16, 634-643. [CrossRef] [PubMed]

44. Utkin, Y.N.; Weise, C.; Kasheverov, I.E.; Andreeva, T.V.; Kryukova, E.V.; Zhmak, M.N.; Starkov, V.G.; Hoang, N.A.; Bertrand, D.; Ramerstorfer, J.; et al. Azemiopsin from Azemiops feae viper venom, a novel polypeptide ligand of nicotinic acetylcholine receptor. J. Biol. Chem. 2012, 287, 27079-27086. [CrossRef] [PubMed]

45. Voevodin, V.; Antonov, A.; Nikitenko, D.; Shvets, P.; Sobolev, S.; Sidorov, I.; Stefanov, K.; Voevodin, V.; Zhumatiy, S. Supercomputer Lomonosov-2: Large Scale, Deep Monitoring and Fine Analytics for the User Community. Supercomput. Front. Innov. 2019, 6, 4-11. 